\title{
Preliminary trial of surgery after chemotherapy for advanced gastric cancer with peritoneal dissemination
}

\author{
MANABU YAMAMOTO $^{1,2}$, AYUMI MATSUYAMA ${ }^{1}$, KEIJI YOSHINAGA ${ }^{1}$, \\ TOKIOMI IWASA $^{1}$, SHINICHI TSUTSUI ${ }^{1}$ and TERUYOSHI ISHIDA ${ }^{1}$ \\ ${ }^{1}$ Department of Surgery, Hiroshima Red Cross Hospital, Naka-ku, Hiroshima 730-8619; \\ ${ }^{2}$ Department of Surgery, Saiseikai Yahata General Hospital, Higashi-ku, Yahata, Kitakyushu 805-0050, Japan
}

Received September 7, 2011; Accepted November 23, 2011

DOI: $10.3892 / \mathrm{ol} .2011 .525$

\begin{abstract}
Systemic chemotherapy is the key treatment for patients presenting with advanced gastric cancer with peritoneal dissemination. In certain cases, adjuvant surgery following systemic chemotherapy may result in improved long-term survival. This study aimed to evaluate the efficacy of adjuvant surgery following response to chemotherapy for advanced gastric cancer with peritoneal dissemination. The study included 13 patients with a diagnosis of advanced gastric cancer with peritoneal dissemination. Of the 13 patients, 5 patients underwent surgery after the peritoneal dissemination was eradicated following systemic chemotherapy (group S), while the remaining 8 patients continued to receive systemic chemotherapy due to persistent peritoneal dissemination (group C). All 13 patients underwent treatment between October 2008 and February 2011. The chemotherapy regimen included cis-diamminedichloride platinum plus S-1 (an oral fluoropyrimidine) or docetaxel plus S-1 for all patients. The median overall survival time of the 13 patients was 660 days. The survival time did not differ with patient response to chemotherapy. The median survival time of the patients in group $\mathrm{S}$ was 794 days, which was significantly higher than that of the patients in group $\mathrm{C}$ (505 days; $\mathrm{p}<0.05$ ). One- and 2-year survival was observed in 100 and $60 \%$ of patients, respectively, in group S, and 66.7 and $0 \%$ of patients in group C. In conclusion, adjuvant surgery led to longer survival in patients having advanced gastric cancer with peritoneal dissemination, which was eradicated following systemic chemotherapy.
\end{abstract}

\section{Introduction}

The prevalence of gastric cancer is higher in East Asia, Eastern Europe, and Central and South America compared to other

Correspondence to: Dr Manabu Yamamoto, Department of Surgery, Saiseikai Yahata General Hospital, 5-9-27 Haruno-machi, Higashi-ku, Yahata, Kitakyushu 805-0050, Japan

E-mail: yamamoto-m@yahata.saiseikai.or.jp

Key words: gastric cancer, peritoneal dissemination, surgery countries. Worldwide, gastric cancer ranks second among all causes of mortality from cancer, with approximately 7,000,000 deaths confirmed annually (1). In Japan, it is one of the most frequent causes of cancer mortality, despite notable advances in diagnosis and treatment (2). Outcomes are extremely poor in patients with unresectable gastric cancer, whose median survival time ranges from 3 to 5 months even with the best supportive care $(3,4)$. Numerous randomized controlled trials of various treatment regimens were previously reported, including trials of 5-fluorouracil, doxorubicin and mitomycin (5), epirubicin and cis-diamminedichloride platinum (CDDP) in combination with a continuous infusion of 5-fluorouracil (6), and 5-fluorouracil and CDDP (7). However, the trials documented median survival times of less than 1 year. Recently, two randomized controlled trials were reported from Japan $(8,9)$. One was the Japanese Clinical Oncology Group 9912 trial, which demonstrated S-1 (an oral fluoropyrimidine) to be superior to the continuous infusion of 5-fluorouracil with respect to overall survival (OS). The other was the SPIRITS trial, which identified CDDP plus S-1 as the standard chemotherapy regimen for advanced or recurrent gastric cancer in Japan (8).

The treatment of gastric cancer with docetaxel, either as a monotherapy (10) or in combination with other agents (11-13), has shown promising results. In addition, phase I and II studies of combination therapy with docetaxel plus $\mathrm{S}-1$ have been performed for patients with advanced or recurrent gastric cancer $(14,15)$. Recently, phase III studies were reported at the 2011 Gastrointestinal Cancers Symposium co-sponsored by the American Society of Clinical Oncology (16).

Systemic chemotherapy is the standard choice of treatment for patients with stage IV gastric cancer. In certain cases, combination chemotherapy (CDDP or docetaxel plus S-1) results in long-term survival and, in selected cases, adjuvant surgery may result in improved long-term survival. Surgical resection has been classified as curative (no evidence of remaining disease following surgery; group S). Systemic chemotherapy was continued for those patients in whom laparoscopy or imaging results revealed non-curative surgery (group C).

This study therefore aimed to evaluate the efficacy of surgery or continued chemotherapy in patients with advanced gastric cancer with peritoneal dissemination, following response to initial chemotherapy. 
Table I. The characteristics of patients with advanced gastric cancer with peritoneal dissemination (group S).

\begin{tabular}{|c|c|c|c|c|c|c|c|c|c|c|}
\hline \multirow{2}{*}{$\begin{array}{l}\text { Case } \\
\text { no. }\end{array}$} & \multirow[t]{2}{*}{ Age } & \multirow[t]{2}{*}{ Gender } & \multicolumn{4}{|c|}{ Clinical stage } & \multirow{2}{*}{$\begin{array}{c}\text { Regimen } \\
\text { before surgery }\end{array}$} & \multirow[t]{2}{*}{ No. of cycles } & \multirow[t]{2}{*}{ Response } & \multirow{2}{*}{$\begin{array}{l}\text { Surgical } \\
\text { curability }\end{array}$} \\
\hline & & & $\mathrm{T}$ & $\mathrm{N}$ & $\mathrm{M}$ & $\mathrm{P}(\mathrm{CY})$ & & & & \\
\hline 1 & 59 & $\mathrm{~F}$ & 3 & 2 & 0 & 1 & TXT+S-1 & 2 & SD & R0 \\
\hline 2 & 68 & M & 3 & 2 & 0 & 1 & $\mathrm{TXT}+\mathrm{S}-1$ & 5 & SD & R0 \\
\hline 3 & 59 & $\mathrm{~F}$ & 3 & 1 & 0 & 1 & $\mathrm{TXT}+\mathrm{S}-1$ & 10 & PR & $\mathrm{R} 0$ \\
\hline 4 & 57 & M & 3 & 1 & 0 & 1 & $\mathrm{CDDP}+\mathrm{S}-1$ & 4 & PR & R0 \\
\hline 5 & 65 & $\mathrm{M}$ & 4 & 1 & 0 & 1 & $\mathrm{CDDP}+\mathrm{S}-1$ & 4 & PR & R0 \\
\hline
\end{tabular}

TXT, docetaxel; CDDP, cis-diamminedichloride platinum; SD, stable disease; PR, partial response; R0, no residual tumor.

Table II. The characteristics of patients with advanced gastric cancer with peritoneal dissemination (group C).

\begin{tabular}{|c|c|c|c|c|c|c|c|c|c|c|}
\hline \multirow{2}{*}{$\begin{array}{l}\text { Case } \\
\text { no. }\end{array}$} & \multirow[t]{2}{*}{ Age } & \multirow[t]{2}{*}{ Gender } & \multicolumn{4}{|c|}{ Clinical stage } & \multirow[t]{2}{*}{ Regimen } & \multirow{2}{*}{$\begin{array}{c}\text { No. of cycles } \\
\text { on 1st line }\end{array}$} & \multirow{2}{*}{$\begin{array}{l}\text { Response } \\
\text { on 1st line }\end{array}$} & \multirow[t]{2}{*}{ Surgery } \\
\hline & & & $\mathrm{T}$ & $\mathrm{N}$ & $\mathrm{M}$ & $\mathrm{P}(\mathrm{CY})$ & & & & \\
\hline 1 & 38 & $\mathrm{M}$ & 3 & 1 & 0 & 1 & $\mathrm{TXT}+\mathrm{S}-1$ & 3 & SD & No \\
\hline 2 & 57 & M & 3 & 2 & 0 & 1 & $\mathrm{TXT}+\mathrm{S}-1$ & 12 & PR & No \\
\hline 3 & 42 & $\mathrm{~F}$ & 4 & 0 & 0 & 1 & $\mathrm{TXT}+\mathrm{S}-1$ & 3 & SD & No \\
\hline 4 & 53 & $\mathrm{~F}$ & 3 & 2 & 0 & 1 & $\mathrm{TXT}+\mathrm{S}-1$ & 7 & PR & No \\
\hline 5 & 41 & $\mathrm{M}$ & 3 & 2 & 0 & 1 & $\mathrm{CDDP}+\mathrm{S}-1$ & 3 & PD & No \\
\hline 6 & 61 & $\mathrm{M}$ & 3 & 2 & 1 & 1 & $\mathrm{CDDP}+\mathrm{S}-1$ & 4 & PD & No \\
\hline 7 & 71 & $\mathrm{~F}$ & 4 & 2 & 0 & 1 & $\mathrm{CDDP}+\mathrm{S}-1$ & 1 & $\mathrm{SD}$ & No \\
\hline 8 & 39 & $\mathrm{M}$ & 3 & 2 & 0 & 1 & $\mathrm{CDDP}+\mathrm{S}-1$ & 6 & PR & No \\
\hline
\end{tabular}

TXT, docetaxel; CDDP, cis-diamminedichloride platinum; SD, stable disease; PR, partial response; PD, progressive disease.

\section{Materials and methods}

Patients. The study included 13 patients with advanced gastric cancer with peritoneal dissemination treated between October 2008 and March 2011 at the Hiroshima Red Cross Hospital, Japan. Initially, all 13 patients were diagnosed with unresectable advanced gastric cancer. Five patients underwent curative gastrectomies following the disappearance of peritoneal dissemination in response to chemotherapy with CDDP plus S-1 or docetaxel plus S-1 (group S). The remaining 8 patients with persistent peritoneal dissemination continued to receive systemic chemotherapy (group C).

Treatment regimen. For the S-1 and CDDP regimen, S-1 $\left(80 \mathrm{mg} / \mathrm{m}^{2}\right)$ was administered orally for 3 weeks, followed by a drug-free interval of 2 weeks. CDDP $\left(60 \mathrm{mg} / \mathrm{m}^{2}\right)$ was diluted in $500 \mathrm{ml} 0.9 \%$ saline and administered as a 2 -h infusion on day 8 after the hydration of each cycle (i.e., every 5 weeks). For the docetaxel and S-1 regimen, S-1 $\left(80 \mathrm{mg} / \mathrm{m}^{2}\right)$ was administered orally for 2 weeks, followed by a drug-free interval of 1 week. Docetaxel $\left(40 \mathrm{mg} / \mathrm{m}^{2}\right)$ was diluted in $100 \mathrm{ml} 0.9 \%$ saline and administered as a 1-h infusion on day 1 of each cycle (i.e., every 3 weeks).

Responses were classified on the basis of the guidelines of the Response Evaluation Criteria in Solid Tumors (RECIST)
(17) and the Japanese Gastric Cancer Association (18). To assess responses, the tumor area was measured every 4-6 weeks on a 5-mm slice computed tomography scan for all measurable lesions. Toxicity was graded on the basis of the Common Terminology Criteria for Advanced Events version 3.0 (19). Informed consent was received from all patients.

Indications for adjuvant surgery. The indications for curative resection were anticipated on the basis of the response to chemotherapy. Such indications included the absence of distant metastases, such as peritoneal dissemination, extensive lymph node metastases or lung metastases. Surgery was undertaken after laparoscopy confirmed the disappearance of the nodules of peritoneal dissemination. CDDP plus S-1, docetaxel plus S-1, or S-1 alone was planned for the 5 patients until recurrence or for 1 year after surgery.

\section{Results}

Patient characteristics. The characteristics of patients in groups $\mathrm{S}$ and $\mathrm{C}$ are shown in Tables I and II, respectively. The median age of patients in group $\mathrm{S}$ was 61.6 years, while that of patients in group $\mathrm{C}$ was 50.3 years.

The 5 cases shown in Table I (group S) underwent curative resection following the disappearance of peritoneal dissemi- 


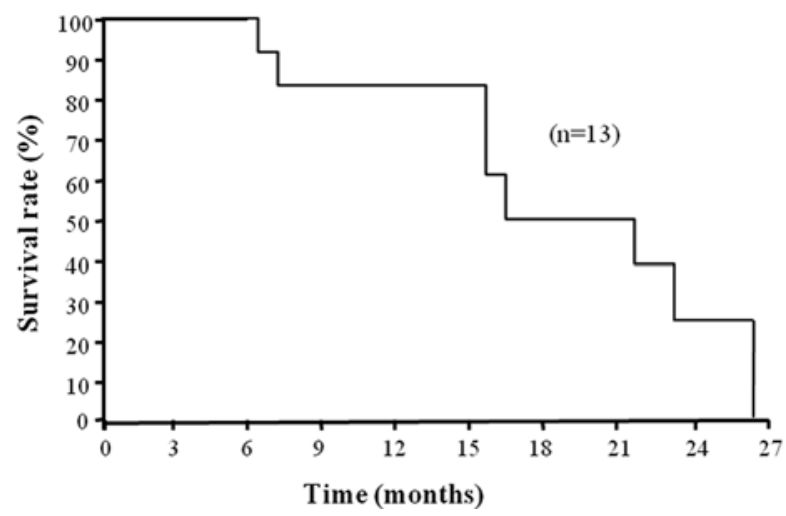

Figure 1. Overall survival time of all 13 patients is shown. The median survival time was 660 days.

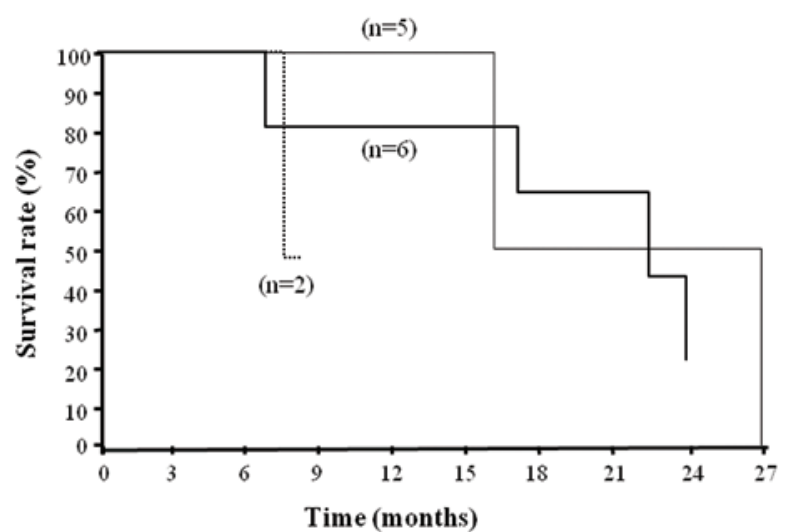

Figure 2. Comparison between overall survival with partial response (PR), stable disease (SD) and progressive disease (PD). The survival curve of patients with PR (thick curve), SD (thin curve) and PD (dotted curve) is shown.

nation in response to systemic chemotherapy. The median duration of preoperative chemotherapy was 4.6 months per patient (range, 6-30 weeks). Patients were assessed for their response following surgery. No cases demonstrated a complete response $(\mathrm{CR})$ or progressive disease $(\mathrm{PD})$, while $3(60 \%)$ demonstrated a partial response (PR) and $2(40 \%)$ demonstrated stable disease (SD). One of the 5 (20\%) patients developed pancreatic fistula following surgery. At a median follow-up of 664 days, the median duration of OS was 794 days in these patients.

The 8 cases shown in Table II (group C) received systemic chemotherapy without surgery. The median duration of first-line chemotherapy was 4.5 months per patient (range, 5-30 weeks), following which patients were assessed for their response. No case of CR was observed, while PR was observed in 3 cases $(37.5 \%)$, SD in $3(37.5 \%)$ and PD in $2(25.0 \%)$. At a median follow-up of 376 days, the median duration of OS was 505 days in these patients.

Comparison of OS in patients with various responses. The survival time of the patients is shown in Fig. 1. The median was 660 days, at a median follow-up of 524 days. The survival time of patients with PR did not differ from that of patients with SD or PD (Fig. 2).

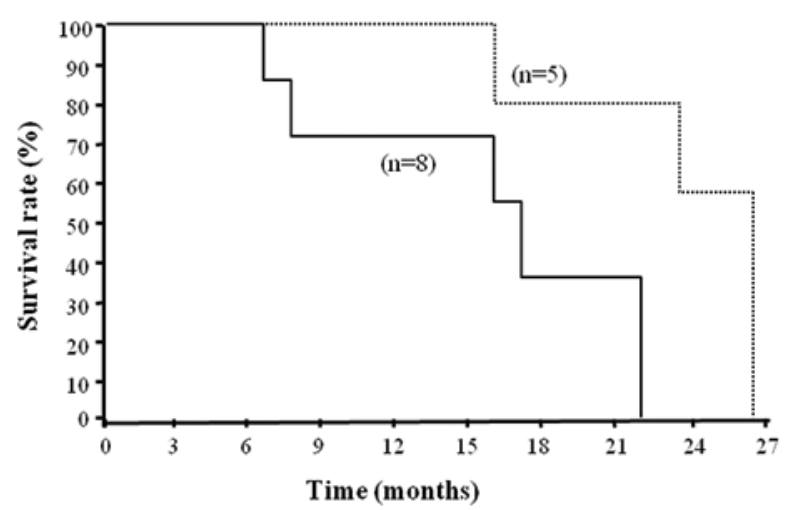

Figure 3. The survival curve of patients in groups $\mathrm{S}$ (dotted curve) and $\mathrm{C}$ (thick curve) is shown. The median survival times in groups $\mathrm{S}$ and $\mathrm{C}$ were 794 and 505 days, respectively.

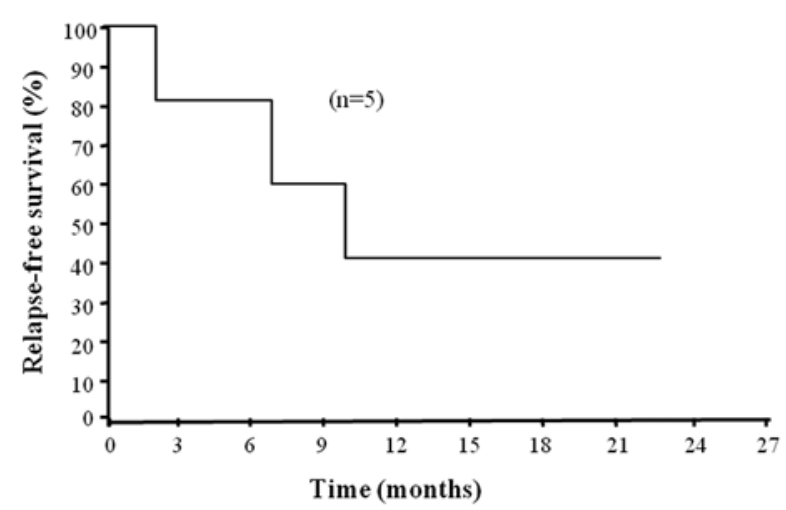

Figure 4. The relapse-free survival (RFS) in group $\mathrm{S}$ is shown. The median RFS was 294 days. Day 1 is defined as the day of surgery.

Comparison of OS between patients in groups $S$ and $C$. The median survival time of patients in group S was 794 days, which was significantly longer than that in group $\mathrm{C}$ (505 days, Fig. 3, p<0.05). One- and 2-year survival was observed in 100 and $60 \%$ of patients, respectively, in group S, and 66.7 and $0 \%$ of patients, respectively, in group C. In group $\mathrm{S}$, relapse-free survival (RFS) was 294 days (Fig. 4).

\section{Discussion}

Various treatment regimens for advanced or recurrent gastric cancer have been developed $(5,6,9)$ and have improved patient survival. In Japan, the combination of docetaxel plus S-1 or CDDP plus S-1 is effective as a first-line chemotherapy for advanced or recurrent gastric cancer. In the SPIRITS and STAT studies, the median survival times were reported to be 13.0 and 12.8 months, respectively, and the median time to tumor progression was 5.0 and 5.3 months, respectively $(9,16)$. Although advances in chemotherapy have resulted in improved long-term survival, a number of patients have required alternative or adjuvant treatments or a reduction in dose levels due to drug resistance or adverse effects. The patients were usually administered another regimen in such cases (second- or third-line). 
Although chemotherapy is the standard treatment for unresectable advanced gastric cancer, it may prove inadequate in certain cases. In particular, advanced gastric cancer with peritoneal dissemination has a poor prognosis. The actual rate of CR with S-1-based combination chemotherapy has been found to be relatively low $(8,15,20,21)$. Peritoneal dissemination is the greatest barrier to an improved prognosis for advanced gastric cancer. In this study, peritoneal dissemination disappeared macroscopically in 5 cases following systemic chemotherapy. However, this disappearance may have been temporary and macroscopic. Therefore, while systemic chemotherapy may have been effective at that time, it may have been insufficient to prevent the recurrence of peritoneal dissemination at a later date.

Curative surgery should be undertaken after a reduction in tumor size, and before the appearance of drug resistance. In this study, the average duration of preoperative chemotherapy was 4.5 months. It is difficult to evaluate the period of preoperative chemotherapy due to the small sample size. However, the duration of preoperative systemic chemotherapy using docetaxel plus S-1 or CDDP plus S-1 may indicate time to progression for advanced gastric cancer (5-5.3 months).

In this study, the survival time of patients with peritoneal dissemination who underwent surgery following preoperative chemotherapy was significantly longer than that of patients treated with chemotherapy alone. However, the effects of surgery with combined chemotherapy such as CDDP plus S-1 or docetaxel plus S-1 were weaker than expected, with an RFS of only 9.4 months. Recently, Suzuki et al reported that the effect of adjuvant surgery on stage IV gastric cancer was weaker in cases with peritoneal dissemination than in cases with lymph node or liver metastases (22).

The ACTS-GC trial advocated adjuvant chemotherapy following curative resection of advanced gastric cancer. Therefore, patients were administered S-1 for 1 year following curative resection of stage II and III gastric cancer according to the Japanese Classification. The 5 cases in this study were administered CDDP plus S-1, docetaxel plus S-1 or S-1 alone following surgery. However, 2 of these patients were not administered the combined chemotherapy for more than 3 months. In the ACTS-GC trial, $66.4 \%$ of patients were administered S-1 alone for 1 year (23). Kodera et al demonstrated that CDDP plus S-1 was extremely toxic as a postoperative treatment (24). Considering these results, it is difficult to prescribe post-gastrectomy combination chemotherapy for Japanese gastric cancer patients. To improve the prognosis of gastric cancer with peritoneal dissemination, strong combined preoperative chemotherapy (for example, docetaxel and CDDP plus S-1) (25) should be administered rather than postoperative combination chemotherapy with docetaxel plus S-1 or CDDP plus S-1.

This study aimed to evaluate the efficacy of adjuvant surgery following an initial response to systemic chemotherapy for advanced gastric cancer with peritoneal dissemination. The OS of patients was prolonged following curative surgery. To prove the efficacy of adjuvant surgery, a randomized controlled study with a larger sample of patients is necessary. A number of obstacles remain to be addressed, including the selection of combination drugs, the timing of adjuvant surgery, and the selection of postoperative chemotherapy.

\section{References}

1. Kamanger F, Dores GM and Anderson WF: Patterns of cancer incidence, mortality, and prevalence across five continents: defining priorities to reduce cancer disparties in different geographic regions of the world. J Clin Oncol 24: 2137-2150, 2006.

2. Inoue $M$ and Tsugane S: Epidemiology of gastric cancer in Japan. Postgrad Med J 81: 419-424, 2005.

3. Murad AM, Santiago FF, Petroianu A, Rocha PR, Rodrigues MA and Rausch M: Modified therapy with 5-fluorouracil, doxorubicin, and methotrexate in advanced gastric cancer. Cancer 72 : 37-41, 1993.

4. Glinelinus B, Ekstrom K, Hoffman K, Graf W, Sjoden PO, Haglund U, Svensson C, Enander LK, Linne T, Sellstrom H and Heuman R: Randomized comparison between chemotherapy plus best supportive care with best supportive care in advanced gastric cancer. Ann Oncol 8: 163-168, 1997.

5. MacDonald JS, Schein PS, Woolley PV, Smythe T, Ueno W, Hoth D, Smith F, Boiron M, Gisselbrecht C, Brunet R and Lagarde C: 5-Fluorouracil, doxorubicin, and mitomycin (fam) combination chemotherapy for advanced gastric cancer. Ann Intern Med 93: 533-536, 1997.

6. Findlay M, Cuningham D, Norman A, Mansi J, Nicolson M, Hickish T, Nicolson V, Nash A, Sacks N, Ford H, Carter R and Hill A: A phase II study in advanced gastro-esophageal cancer using epirubicin and cisplatin in combination with continuous infusion 5-fluorouracil (ECF). Ann Oncol 5: 609-616, 1994.

7. Ohtsu A, Shimoda Y, Shirao K, Boku N, Hyodo I, Saito H, Yamamichi N, Miyata Y, Ikeda N, Yamamoto S, Fukuda H and Yoshida S: Randomized phase III trial of fluorouracil alone vs. fluorouracil plus cisplatin vs. uracil and tergafur plus mitomycin in patients with unresectable, advanced gastric cancer: the Japan Clinical Oncology Study (JCOG9205). J Clin Oncol 21: 54-59, 2003.

8. Koizumi W, Narahara H, Hara T, Takegane A, Akiya T, Takagi M, Miyashita K, Nishizaki T, Kobayashi O, Takiyama W, et al: S-1 plus cisplatin vs. S-1 alone for first-line treatment of advanced gastric cancer (SPIRITS): A phase III trial. Lancet Oncol 9: 215-221, 2009.

9. Boku N, Yamamoto S, Fukuda H, Shirao K, Doi T, Sawaki A, Koizumi W, Saito H, Yamaguchi K, Takiuchi H, Nasu J and Ohtsu A: Gastrointestinal Oncology Study Group of the Japan Clinical Oncology Group: Fluorouracil vs. combination of irinotecan plus cisplatin vs. S-1 in metastatic gastric cancer. A randomized phase 3 study. Lancet Oncol 10: 1063-1069, 2009.

10. Einzig AI, Neuberg D, Remick SC, Karp DD, O'Dwyer PJ, Stewart JA, Benson AB 3rd: Phase II trial of docetaxel (taxotere) in patients with adenocarcinoma of the upper gastrointestinal tract previously untreated with cytotoxic chemotherapy: the Eastern Cooperative Oncology Group (ECOG) results of protocol el293. Med Oncol 13: 87-93, 2006.

11. Thuss-Patience PC, Kretzchmar A and Reichardt P: Docetaxel in the treatment of gastric cancer. Future Oncol 10: 603-620, 2009.

12. Fushida S, Fujimura T, Oyama K, Yagi Y, Kinoshita J and Ohta T: Feasibility and efficacy of preoperative chemotherapy with docetaxel, cisplatin and S-1 in gastric cancer with para-aortic lymph node metastases. Anticancer Drug 20: 752-756, 2009.

13. Zang DY, Yang DH, Kim MJ, Jang KM, Hwang SW, Yoo KS, Han T, Kim HY, Kim HJ, Kwon JH, et al: Dose-finding study of docetaxel, oxaliplatin, and S-1 for patients with advanced gastric cancer. Cancer Chemother Pharmacol 64: 877-883, 2009.

14. Yoshida K, Hirabayashi N, Takiyama W, Ninomiya M, Takakura N, Sakamoto J, Nishiyama M and Toge T: Phase I study of combination therapy with S-1 and docetaxel (TXT) for advanced or recurrent gastric cancer. Anticancer Res 24: 1843-1851, 2004.

15. Yoshida K, Ninomiya M, Takakura N, Hirabayashi N, Takiyama W, Sato Y, Toda S, Terashima M, Gotoh M, Sakamoto J and Nishiyama M: Phase II study of docetaxel and S-1 combination therapy for advanced gastric cancer. Clin Cancer Res 12: 3402-3407, 2006.

16. Kim YH, Koizumi W, Lee KH, Kishimoto T, Chung HC, Hara T, Cho JY, Nakajima T, Kim H and Fujii M: American Society of Clininal Oncology - Gastrointestinal Symposium 2011, Board \#A8. J Clin Oncol 29 (Suppl 4): abs. 7, 2011.

17. Eisenhauer EA, Terasse P, Bogaerts J, Schwartz LH, Sargent D, Ford R, Dancey J, Arbuck S, Gwyther S, Mooney M, et al: New response evaluation criteria in solid tumors: revised RECIST guideline (version 1.1). Eur J Cancer 45: 228-247, 2009. 
18. Japanese Gastric Cancer Association: Japanese classification of gastric carcinoma - 3rd English edition. Gastric Cancer 14: 101-112, 2011.

19. Trotti A, Colevas AD, Setser A, Rusch H, Jaques D, Budach V, Langer C, Murphy B, Cumberline R, Coleman CN and Rubin P: CTCAC v3.0: development of a comprehensive grading system for the adverse effects of cancer treatment. Semin Radiat Oncol 13: 176-181, 2009.

20. Lenz HJ, Lee FC, Haller DG, Singh D, Benson AB 3rd, Strumberg D, Yanagihara R, Yao JC, Phan AT and Ajiani JA: Extended safety and efficacy data on S-1 plus cisplatin in patients with untreated, advanced gastric carcinoma in a multicenter phase II study. Cancer 109: 33-40, 2008.

21. Park SR, Kim HK, Kim CG, Choi IJ, Lee JS, Lee JH, Ryu KW, Kim YW, Bae JM and Kim NK: Phase I/II study of S-1 combined with weekly docetaxel in patients with metastatic gastric carcinoma. Br J Cancer 98: 1305-1311, 2008.
22. Suzuki T, Tanabe K, Taomoto J, Yamamoto H, Tokumoto N, Yoshida $\mathrm{K}$ and Ohdan H: Preliminary trial of adjuvant surgery for advanced gastric cancer. Oncol Lett 1: 743-747, 2010.

23. Sakuramoto S, Sasako M, Yamaguchi T, Kinoshita T, Fujii M, Nashimoto A, Fukukawa H, Nakajima T, Ohashi Y, Imamura H, et al: Adjuvant chemotherapy for gastric cancer with $\mathrm{S}-1$, an oral fluoropyrimidine. N Engl J M 357: 1810-1820, 2008.

24. Kodera Y, Ishikawa A, Yoshikawa T, Kinoshita T, Ito S Yokoyama H, Michizuki Y, Ito H, Tsuburaya A, Sakamoto J and Nakao A: A feasibility study of postoperative chemotherapy with S-1 and cisplatin (CDDP) for gastric carcinoma. Gastric Cancer 13: 197-203, 2010.

25. Fushida S, Fujimura T, Oyama K, Kinoshita J, Fujita H, Ninomiya I and Ohta T: Neoadjuvant chemotherapy combining docetaxel, cisplatin, and S-1 in gastric cancer with para-aortic lymph node metastases: report of five cases. Hepatogastroenterol 57: 1650-1654, 2010. 